\title{
Nationality Differences In Body Mass Index Of Under Tenwest And Central Africa Children Living In Nigeria
}

\author{
Adeoso, A. Olaitan \\ *Department of Nutrition \& Dietetics, Yaba College of Technology, Yaba, Lagos State; Nigeria.
}

\begin{abstract}
Body Mass Index generally is a reflection of a combination of feeding pattern and lifestyle. This study assessed the differences in the body mass index of 120 children of West and Central African origin. This was a descriptive and cross-sectional study of 120 respondents ( $n=70$ Nigerians, 27 Sierra-Leonians, 19 Liberian, 2 Rwandans and 2 Congolese) between ages 2 and 10 randomly selected from Oru town in Ogun State, Nigeria. Anthropometric measurement was doneusing bathroom for weighing them; height was captured with a wooden meter rule while standing, both bare-footed.Logistic regression revealsthat males are 0.715 times less likely to be obese than female, children between age 4-5years are 4 times more likely to be obese than children of the age group 1-3years, children between age 6-10years are also 4 times more likely to be obese than children from the age group 1-3years. Children within the height range 0-91 cm are 2 times more likely to be obese than children above $91 \mathrm{~cm}$. The multiple comparison showed a significant difference of 0.617 in mean between Nigerian children and that of Sierra Leon.The study emphasis the importance of public health training about adequate feeding of children under harsh conditions.
\end{abstract}

Key Words: BMI; Nationalities; Weight; Height; Obesity; underweight

\section{Introduction}

Body Mass Index or Quetelet Index is a measure of relative size based on the mass and height of an individual. The Index was devised by Adolphe Quetelet during the course of developing what he called "social Physics" between 1830 and 1850.

The Body Mass Index for a person is defined as their body mass divided by the square of the height with thee value universally being given in units of $\mathrm{Kg} / \mathrm{m} 2$. It is a simple method to assess how much the recorded body weight departs from what is healthy or desirable for a person of that height. ${ }^{1}$

Body Mass Index (BMI) is a number indicating the level of fatness or weight range of an individual. Body mass Index (BMI) for children and teenagers is based on sex and age. BMI is calculated using a child's weight and height then it is used to find the corresponding BMI for Age. The BMI-for-Age percentile of a child shows how a child's weight compares with that of other children of the same age and sex i.e. a Reference Standard. Malnutrition which results into stunting and wasting is a major problem among children in Africa. Though data on obesity and overweight and its social variation among children are still scares, a study carried out at the University of NigeriaTeaching Hospital reported that one out of every35 Nigerian children has BMI below $5^{\text {th }}$ percentile although the values differ across other Africa countries ${ }^{2}$

According to Mijailovic V., Micic D., and Mijailovic M.Adolescence seems to be one of the critical periods for the development of obesity. ${ }^{3}$ Development during this period is related to health status in adulthood and a strong relationship between socio-demographic factor and obesity has been shown in some studies 4,5 . Ethnic and regional obesity differences have been investigation carried out in the U.S. and Sri-Lanka and Australian children reported that genetic factors affect secular growth ${ }^{6,7}$. Rush et al ${ }^{8}$ recommended using Free Fat Mass (FFM) instead of BMI while other studies believed that separate growth charts should be used for Moroccan and Turkish children living in the Netherlands, ${ }^{9,10}$

Recent studies in Britain have indicated that females between ages 12 and 16 have a higher BMI than males of the same by $1.0 \mathrm{Kg} /$ metre square on average ${ }^{11}$

Clinically, the BMI of a childis not enough to evaluate long term weight status because height and weight of children change with growth. This a major reason why the method for calculating adults' differs from that of children as adults no longer grow. ${ }^{12}$

BMI in children and teenagers is age and sex specific i.e. BMI-For-Age. Data required for calculating BMI for Children and Teenagers are accurate Weight and height as well as sex of the child ${ }^{12 .}$ The data is imputed into the programmed calculator based on standards set by the Centre for Disease Prevention in the United States and the result is generated instantly. After BMI calculation for children and teenagers, the BMI number is plotted on the US Centre for Disease Control BMI-For-Age growth charts for both boys and girls to obtain ranking. Percentiles are the most commonly used indicator to assess the size and growth patterns of individual children. The percentile indicates the relative position of the child's BMI among other children, this process is acceptable for children age two (2) to twenty (20). 
The ranking of percentiles designed by the Centre for Disease Prevention and Control is as follows:

I Underweight- less than the $5^{\text {th }}$ Percentile

II Health weight- $5^{\text {th }}$ Percentile to the $85^{\text {th }}$ Percentile

III Overweight- $85^{\text {th }}$ to less than $95^{\text {th }}$ Percentile

IV Obese- equal or greater than $95^{\text {th }}$ Percentile

For example a 10 year-old boy with a weight of $29 \mathrm{~kg}$ will have a BMI of 14.8 at the $12^{\text {th }}$ Percentile for boys, he is considered healthy in weight. However, a boy in the $65^{\text {th }}$ Percentile is considered to have weight greater than some children of the same age and sex but not particularly overweight. ${ }^{12}$

BMI is both age and sex specific for children and Teenagers for the following reasons:

i) The amount of body fat changes with age

ii) The amount of body fat differs between girls and boys.

It is paramount to note however, that healthy weight range cannot be provided for children and teenagers like adults because healthy weight range changes with each month of age for each sex and healthy weight range changes as height increases.

Adult BMI calculators cannot be used for children because it provides only the BMI number and not the BMI Age and sex specific percentile that is used to interpret BMI and determine the weight for children and teenagers.

Two children may have the same BMI value but one may be considered obese because the interpretation of BMI varies by age and sex especially when the children are not exactly the same age and of the same sex.

\section{Objective}

The study was carried out to determine the distinguishing factors between the BMI of a group of nonnationale children living in a rural area and to compare the BMI distribution among children from five African nationsliving in Nigeria. The need for the study arose due to the increasing cases of child obesity and associated diseases in the country.

\section{Materials And Methods}

This was a descriptive and cross sectional study performed on 120 children between ages 1 and 10 from five different nations (19 Liberians; 27 Sierralonians; 2 Congolese; 2 Rwandans; 70 Nigerians). This sample size of the foreigners was based on the population available at the time the data was collected at the Refugee camp at Ijebu- South West Nigeria. The Nigerian children were randomly selected in surulere Local Development Council in Lagos State due after parents' consent. Questionnaires which contain relevant Socio economic conditions, food consumption pattern and health history were filled for each child by the researchers.

Weight measurement was carried using bathroom scales for weight while standing upright on the scale without wearing shoes and on light cloths to the nearest $0.1 \mathrm{~kg}$. Height was measured while standing bare-footed on the floor against the height-gauge placed against a wall and measuring tape was wound round to measure the arm circumference.

Body Mass Index was calculated by in-putting data for each child as requested by a special software (WHO Anthro) which automatically brings-up the result.

The estimations of the prevalence of overweight and obesity were based on the cut-off values set by the American Centre for Disease Control and Prevention (CDC) i.e. values in excess of the $85^{\text {th }}$ and $95^{\text {th }}$ percentiles respectively. SPSS 20.0 software was used for the data analysis, ANOVA and multinominal logistic regression were used for the analysis. $\mathrm{P}$ values under 0.05 were considered to indicate statistical significance.

\section{Summary Of Results/ Discussion}

Results shows that a number of children that are obese are 21 , where 4 are between the age 1-3years which involves 3 foreigners and only one Nigerian, 8 are between the age 4-5years which involves 5 Nigerians and 3 foreigners and 9 are between the ages 6-10years involving 6 Nigerians and 3 foreigners. Also the number of children that are overweight is 20, where 2 are between the age 1-3years which were Nigerian, 2 are between the age 4-5years which were Nigerians and 15 are between the age 6-10years which involves 14 Nigerians and one foreigner. The results also revealed that the numbers of children that have normal weight are 59, where 8 are between the age 1-3years where 4 were Nigerians and 4 were foreigners, 13 are between the age 4-5years involving 5 Nigerians and 8 foreigners and 39 are between the age 6-10years involving 27 Nigerians and 12 foreigners. Finally the numbers of children that are underweight are 19, where 5 are between the age 1-3years involving only the foreigners, 8 are between the age 4-5years involving 6 Nigerians and 2 foreigners and 6 are between the age 6-10years involving 2 Nigerians and 4 foreigners. 
The regression model is given as; weight $=\mathbf{- 1 1 . 7 7 1}+\mathbf{0 . 9 2 3}$ age $+\mathbf{0 . 2 3 6}$ height $+\mathbf{0 . 0 3 4}$ arm circumference, which implies that a unit increase in height, age and arm circumference, there is an increase of $0.923,0.236$ and 0.034 increase in weight respectively. If all the explanatory variables are kept constant, i.e. zero, weight is $-11.771 \mathrm{~kg}$.

From the binary logistic regression it shows that males are 0.715 times less likely to be obese than female, also children between the age group 4-5years are 4 times more likely to be obese than children of the age group 1-3years, children between the age group 6-10years are also 4 times more likely to be obese than children from the age group 1-3years, foreigners are 0.927 less likely to be obese than Nigerian children, children within the height range $0-91 \mathrm{~cm}$ are 2 times more likely to be obese than children within the height range $91 \mathrm{~cm}$ and above and children within the weight range $0-70.99 \mathrm{~kg}$ are 0.305 times less likely to be obese than children above that weight range.

Table 1 indicates Age and sex distribution. The breakdown indicates that there are $61(50.8 \%)$ males and $59(49.2 \%)$ females within the sample. For age range $1-3 y r s, 6.7 \%$ represents males and $5.8 \%$ represents females with total of $12.5 \%$ of the total sample, for age range $4-5 y r s, 15 \%$ represents males and $14.2 \%$ represents female with a total of $29.2 \%$ of the total sample, and for age range 6 -10yrs, $29.2 \%$ represents males and $28.3 \%$ represents female with a total of $57.5 \%$ of the total sample.

From table 2, it can be deduced that 20 children are above the standard weight i.e. overweight; 20 are within $85-94^{\text {th }}$ percentile; 51 are within $5-84^{\text {th }}$ percentile and 19 below the $5^{\text {th }}$ percentile.

Table 3 indicates that 4 out of the 8 respondents with normal weight are Nigerians while 4 are foreigners. More of the foreigners are either underweight, overweight or obese which implies that more of the foreigners are at health risk, while table 4 that 5 out of the 13 respondents with normal weight are Nigerians while 8 are foreigners. More of the respondents that are underweight, overweight or obese are foreigners which imply that more of the foreigners are at health risk.

Binary Logistic regression shows that males are 0.715 times less likely to be obese than female, also children between the age group 4-5years are 4 times more likely to be obese than children of the age group 13years, children between the age group 6-10years are also 4 times more likely to be obese than children from the age group 1-3years, foreigners are 0.927 less likely to be obese than Nigerian children, children within the height range $0-91 \mathrm{~cm}$ are 2 times more likely to be obese than children within the height range $91 \mathrm{~cm}$ and above.

\section{Conclusion}

Since all the output are not it means that there is no differences between the BMIs of males and females, Nigerians and foreigners, heights, weights, arm circumference and age range.

\section{References}

[1]. American Centre for Disease Prevention and Control.

[2]. Agozie C. Ubesie, Ngozi S. et al (2011). 10years retrospective review of Under-five Protein- Energy- malnutrition admitted at the University of Nigeria Teaching Hospital

[3]. Mijailovic V., Micic D., Mijailovic M. Effect of childhood and adolescent obesity on morbidity in adult life. Journal of Pediatric Endocrinology 2001; 14: 1339-1344.

[4]. Eknoyan, Garabed 2007(Adolphe Quetelet (1796-1874)“The average man and indices of obesity”. Nephrology Dialysis Transplantation.

[5]. Popkin B. M.-The Nutrition transition and obesity in the developing world. American Journal of Nutrition 2001; 131: 8715-8735.

[6]. Sibai A. M., Hwalla N, AdraN.et al. Prevalence of covariates of obesity in Lebanon: finding from the first epidemiological studies. Obesity Resource 2003; 11:13353-1361.

[7]. Wickramasinghe V.P, Cleghorn G.J., Edmiston k.A., et al. Impact of ethnicity upon body composition assessment in Sri Lankan Australian Children. Jour Paediatric Child health, 2005, 41:101-106[Pub Med].

[8]. Rush E.C., Puniani K, Valencia M.E. et al. Estimation of body Fatness from body mass index and bioelectrical impedence: Comparision of New Zealand European, Maori and Pacific Island children. European journal of Clinical Nut 2003, 57:13941401[Pub Med].

[9]. Fredrick A. M. van Buuren S. Jeurissen S. E. et al. Height, weight, body mass index and pubertal development refers as for children of Moroccans origin in the Netherlands. Acta paeditrics 2004, 93: 817-824.

[10]. Musaiger A. O. Overweight and Obesity in Easter Mediterranean Region: Can we Control it? East Mediterranean Health Journal 2004; 10: 789-793

[11]. American Centre for Disease Prevention and Control. Method of BMI calculation

[12]. Freedman D. S. Khan L.K., Serdula M.K. et al. Racial ethnicity differences in secular trends for childhood BMI, weight and height. Obesity (silver-spring) 2006; 14: 301-308.

[13]. Ogeden C. L., Carol M. D. Curtin L. R. et al. prevalence of current and obesity in the U. S.; 1999-2004. JAMA 2006; 295: 15491555 .

[14]. Health survey for England: The Health of Children and young people. Archive 2. Official document.co.uk- Retrieved $16^{\text {th }}$ December 2013.

[15]. Meiz Z., Grummer Strawn L.M. - validity of the body mass index comparison with other body composition screening index for the assessment of body fatness in children and adolescents. American Journal of Clinical Nutrition 2002; 7597-7985

[16]. Eleanor V. Willett et. al. Non-Hodgkin lymphoma and Obesity: a pooled analysis from the Inter-Lymph consortium Int J Cancer. Author manuscript; available in PMC 2014 Feb 18. Published in final edited form as: Int J Cancer. 2008 May 1; 122(9): 2062-2070. doi: $10.1002 / \mathrm{ijc} .23344$. 
TABLE 1: Age Distribution And Sex

\begin{tabular}{|l|l|l|l|l|l|l|l|l|}
\hline PERCENTAGE VALUE & $\mathbf{1 - 3 y r s}$ & $\mathbf{\%}$ & $\mathbf{4 - 5 y r s}$ & $\mathbf{\%}$ & $\mathbf{6 - 1 0 y r s}$ & $\mathbf{\%}$ & Total & Total \% \\
\hline Male & 8 & 6.7 & 18 & 15 & 35 & 29.2 & 61 & 50.8 \\
\hline Female & 7 & 5.8 & 17 & 14.2 & 34 & 28.3 & 59 & 49.2 \\
\hline Total & 15 & 12.5 & 35 & 29.2 & 69 & 57.5 & 120 & 100 \\
\hline
\end{tabular}

TABLE 2: $\quad$ Expressing The Result By Age And Percentile Value

\begin{tabular}{|l|l|l|l|l|l|l|l|l|}
\hline PERCENTILE VALUE & $\mathbf{1 - 3 y r s}$ & $\mathbf{\%}$ & $\mathbf{4 - 5 y r s}$ & $\mathbf{\%}$ & $\mathbf{6 - 1 0 y r s}$ & $\mathbf{\%}$ & Total & Total \% \\
\hline 95\% or more & 4 & 3.3 & 8 & 6.7 & 9 & 7.5 & 21 & 17.5 \\
\hline $\mathbf{8 5 - 9 4 \%}$ & 2 & 1.7 & 2 & 1.7 & 16 & 13.3 & 20 & 18.1 \\
\hline $\mathbf{5}-\mathbf{8 4 \%}$ & 8 & 6.7 & 13 & 10.8 & 38 & 31.7 & 59 & 49.2 \\
\hline Less than 5\% & 5 & 4.2 & 9 & 7.5 & 6 & 5.0 & 20 & 16.7 \\
\hline Totals & 19 & 15.8 & 32 & 26.7 & 69 & 57.5 & 120 & 100 \\
\hline
\end{tabular}

Table 3:Expressing The Result By Age (1 -3 Yrs) And Nationality

\begin{tabular}{|l|l|l|l|l|l|l|}
\hline PERCENTILE VALUE & Nigerian & \% & Non Nigerian & \% & Total & Total \% \\
\hline 95\% or more & 1 & 5.3 & 3 & 15.8 & 4 & 21.1 \\
\hline $\mathbf{8 5 - 9 4 \%}$ & 2 & 10.5 & 0 & 0 & 2 & 10.5 \\
\hline $\mathbf{5 - 8 4 \%}$ & 4 & 21.1 & 4 & 21.1 & 8 & 42.1 \\
\hline Less than 5\% & 0 & 0 & 5 & 26.3 & 5 & 26.3 \\
\hline Totals & 7 & 36.8 & 12 & 63.2 & 19 & 100 \\
\hline
\end{tabular}

Table 4:Expressing The Result By Age (4 -5 Yrs) And Nationality

\begin{tabular}{|l|l|l|l|l|l|l|}
\hline PERCENTILE VALUE & Nigerian & \% & Non Nigerian & \% & Total & Total \% \\
\hline $\mathbf{9 5 \%}$ or more & 5 & 15.6 & 3 & 9.4 & 8 & 25 \\
\hline $\mathbf{8 5 - 9 4 \%}$ & 2 & 6.3 & 0 & 0 & 2 & 6.3 \\
\hline $\mathbf{5 - 8 4 \%}$ & 5 & 15.6 & 8 & 25 & 13 & 40.6 \\
\hline Less than 5\% & 1 & 3.1 & 8 & 25 & 9 & 28.1 \\
\hline Totals & 13 & 40.6 & 19 & 59.4 & 32 & 100 \\
\hline
\end{tabular}

Table 5:Expressing The Result By Age (6 -10 Yrs) And Nationality

\begin{tabular}{|l|l|l|l|l|l|l|}
\hline PERCENTILE VALUE & Nigerian & \% & Non Nigerian & \% & Total & Total \% \\
\hline $\mathbf{9 5 \%}$ or more & 6 & 8.7 & 3 & 4.3 & 9 & 13 \\
\hline $\mathbf{8 5 - 9 4 \%}$ & 14 & 20.3 & 1 & 1.4 & 15 & 21.7 \\
\hline $\mathbf{5 - 8 4 \%}$ & 27 & 39.1 & 12 & 17.3 & 39 & 56.5 \\
\hline Less than 5\% & 2 & 2.9 & 4 & 5.8 & 6 & 8.7 \\
\hline Totals & 49 & 71 & 20 & 29 & 69 & 100 \\
\hline
\end{tabular}

Table 6: Summary Of Result By Age And Weight Ranking

\begin{tabular}{|l|l|l|l|l|l|l|l|l|}
\hline \multicolumn{2}{|c}{ OBESE } & \multicolumn{2}{c|}{ OVERWEIGHT } & \multicolumn{2}{c|}{ NORMAL WEIGHT } & UNDERWEIGHT \\
\hline & Nigerian & Foreigners & Nigerian & Foreigners & Nigerian & Foreigners & Nigerian & Foreigners \\
\hline 1-3 years & 1 & 3 & 2 & - & 4 & 4 & - & 5 \\
\hline 4-5 years & 5 & 3 & 2 & - & 5 & 8 & 6 & 2 \\
\hline 6-10 years & 6 & 3 & 14 & 1 & 27 & 12 & 2 & 4 \\
\hline Total & 12 & 9 & 18 & 1 & 36 & 24 & 8 & 11 \\
\hline
\end{tabular}

Figure 1: Binary Logistic Regression

\begin{tabular}{|c|c|c|c|c|c|c|c|c|c|}
\hline \multicolumn{10}{|c|}{ Variables in the Equation } \\
\hline & & \multirow[t]{2}{*}{$\mathrm{B}$} & \multirow[t]{2}{*}{ S.E. } & \multirow[t]{2}{*}{ Wald } & \multirow[t]{2}{*}{$\mathrm{df}$} & \multirow[t]{2}{*}{ Sig. } & \multirow[t]{2}{*}{$\operatorname{Exp}(B)$} & \multicolumn{2}{|c|}{ 95\% C.I.for EXP(B) } \\
\hline & & & & & & & & Lower & Upper \\
\hline \multirow{8}{*}{ Step $1^{\mathrm{a}}$} & SEX(1) & -.336 & .519 & .419 & 1 & .518 & .715 & .259 & 1.975 \\
\hline & age(1) & 1.376 & .925 & 2.215 & 1 & .137 & 3.960 & .646 & 24.264 \\
\hline & age(2) & 1.321 & .728 & 3.294 & 1 & .070 & 3.748 & .900 & 15.613 \\
\hline & nation(1) & -.076 & .531 & .020 & 1 & .887 & .927 & .328 & 2.623 \\
\hline & weight(1) & -1.188 & .809 & 2.158 & 1 & .142 & .305 & .062 & 1.487 \\
\hline & height(1) & .592 & .856 & .479 & 1 & .489 & 1.808 & .338 & 9.676 \\
\hline & $\operatorname{arm}(1)$ & -.408 & .576 & .501 & 1 & .479 & .665 & .215 & 2.056 \\
\hline & Constant & -1.258 & .604 & 4.339 & 1 & .037 & .284 & & \\
\hline
\end{tabular}

Figure 2: Multiple Comparisons

\begin{tabular}{l}
\hline $\begin{array}{l}\text { Dependent Variable: BMI remarks } \\
\text { LSD }\end{array}$ \\
\hline (I) Nationality \\
\cline { 3 - 8 }
\end{tabular}


Nationality Differences In Body Mass Index Of Under Tenwest And Central Africa Children Living ..

\begin{tabular}{|l|l|l|l|l|l|l|}
\hline \multirow{4}{*}{} & Congolese & .04 & .673 & .949 & -1.29 & 1.38 \\
\cline { 2 - 7 } & Rwandan & 1.04 & .673 & .124 & -.29 & 2.38 \\
\cline { 2 - 6 } & \multicolumn{4}{|l}{} \\
\hline *. The mean difference is significant at the .05 level. \\
\hline
\end{tabular}

The Post Hoc test shows that there is a significant difference between respondents from Nigeria and Sierra Leon with mean 0.617. This implies that the difference reflects more within the Nigerian population.

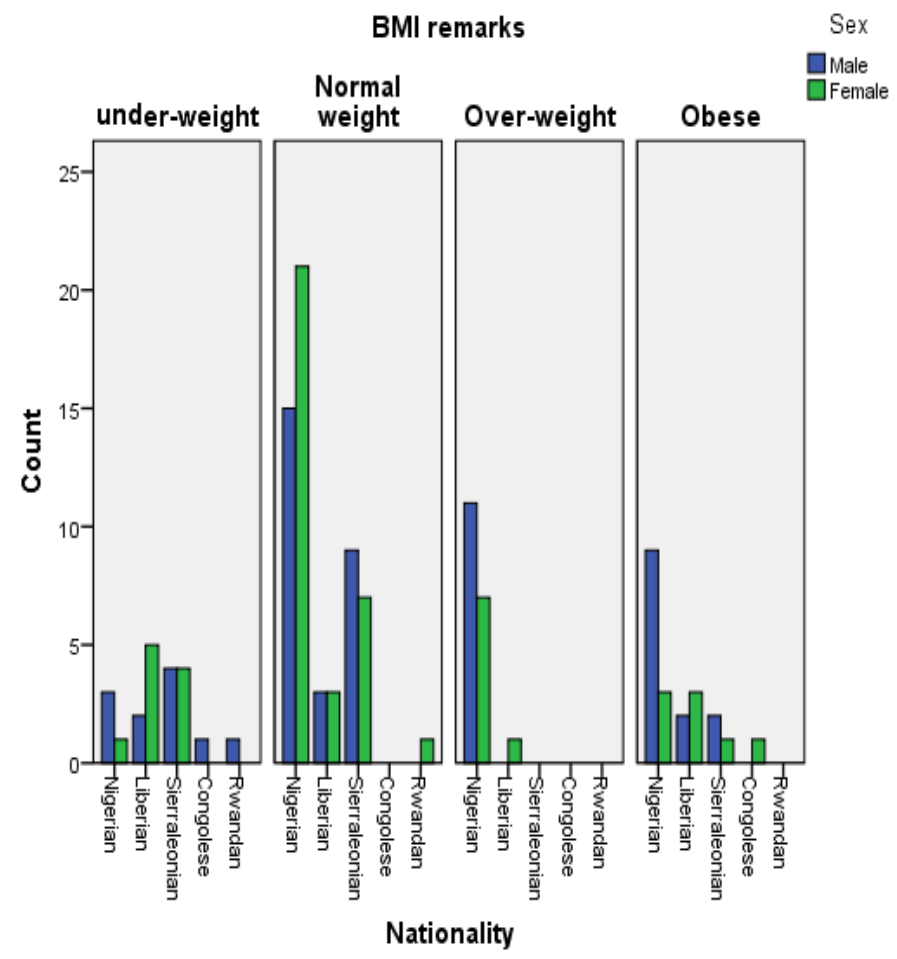

Figure 1 